\title{
Measurement of Dynamic Modulus and Master Curve Modeling of Hot Mix Asphalt from Senegal (West Africa)
}

\author{
Mouhamed Lamine Chérif Aidara ${ }^{1}$, Makhaly Ba ${ }^{1}$, Alan CARTER ${ }^{2}$ \\ ${ }^{1}$ Department of Engineering, University of Thies, Thies, Senegal \\ ${ }^{2}$ Pavement Bituminous Materials Laboratory (LCMB), Ecole de TechnologieSupérieure (ETS), Montreal, Canada \\ Correspondence: Mouhamed Lamine Chérif Aidara, University of Thies, BP 967, Thies, Senegal
}

Received: May 19, 2015

Accepted: July 21, 2015 Online Published: July 30, 2015

doi:10.11114/set.v2i1.936

URL: http://dx.doi.org/10.11114/set.v2i1.936

\begin{abstract}
The main purpose of this paper is to model the master curve of dynamic modulus $\left|E^{*}\right|$ for Hot Mix Asphalt mix designed with aggregate from Senegal named basalt of Diack and quartzite of Bakel. The prediction model used is the Witczak model, used in the Mechanistic-Empirical Pavement Design Guide. A study has been conducted in the Laboratory of Pavements and Bituminous Materials. Six different HMA (BBSG 0/14 mm) were subjected to complex modulus test by tension-compression according to the European or Canadian procedure using the same range of temperatures and frequencies. For each mixture studied the uniqueness of modulus curves in the Cole-Cole or in Black diagrams have shown that the asphalt mixes are thermorheologically simple materials and the Canadian test process is suitable for determining the HMA complex modulus mix designed with the aggregates from Senegal. This implies their tender with the principle of time-temperature equivalence. The test results were used to model the master curves of HMA studied. A correlation with the results of dynamic modulus measured have shown an accuracy of $R^{2}=0,99$ and $p$ $=0,00$ in STATISTICA software, which allows to conclude that the sigmoidal model has good modeling of the dynamic modulus.
\end{abstract}

Keywords: dynamic modulus; basalt of Diack, quartzite of Bakel, Witczak sigmoidal model, Cole-Cole diagram and Black diagram

\section{Introduction}

Bituminous materials such as surface layer, have a viscoelastic behavior that is intermediate between the behavior of a perfect elastic solid and that of a Newtonian liquid (viscous). The deformation of such a material is a function of the applied stress and time. In a linear viscoelastic behavior, the material properties are assumed independent of the applied stress or strain levels. The analysis of the linear viscoelastic behavior under one-dimensional loading of a material is done either by using the rheological models, by the creep loading or steady state dynamic loading (Huang, 2004 and Papagiannakis \& Masad, 2007). Under a sinusoidal dynamic stress loading, the response has a sinusoidal shape but the strain response will lag behind the stress. The complex modulus, $\mathrm{E}^{*}$, is defined as a complex number that relates stress to strain for a linear viscoelastic material subjected to a sinusoidal loading. The absolute value of the complex modulus is commonly referred to as the dynamic modulus (Huang, 2004, Yoder \& Witczak, 1975, DiBenedetto \& Olard, 2003, DiBenedetto \& Corté, 2005 \& Dougan, Mahoney \& Hansen).

There are different methods of laboratory tests to determine the complex modulus of HMA (Huang, 2004, DiBenedetto \& Olard, 2003, DiBenedetto \& Corté, 2005 and Dougan, Mahoney \& Hansen). In 2009, the MTQ established the LC26-700 (2009 test method based on the methods described in AASHTO TP62 07 (2007) and NF EN 12697-26 (2012). However it is not always possible to perform the modulus tests with all the temperatures and frequencies that exist, hence the need to model the results obtained in a master curve. The usefulness of this curve is to predict the modulus of HMA studied at different frequencies and temperatures not taken into account during the test in the laboratory.

To plot a master curve for a HMA, it must be thermorheologically simple. That is to say that the modulus values must have a single curve in the Cole and Cole plan and in the space of Black.

In this paper, the main stages of the LC26-700 procedure will be described at first and then the master curve of dynamic modulus $\left|E^{*}\right|$ of HMA formulated with the basalt of Diack and quartzite of Bakel will be modeled with the Witczak 
sigmoidal model (Witckzak \& Kaloush, 2002).

\section{Material Characterization and Method}

The Dynamic Modulus Test is used to measure the dynamic modulus $\left|E^{*}\right|$ of an HMA mix at different temperatures and loading frequencies. The test can be conducted in a uniaxial or triaxial condition in either compression or tension. However, the majority of tests during the past years were in compression (Papagiannakis \& Masad, 2007). When the test is conducted in compression, the specimen experiences creep, in addition to the dynamic response. In the analysis, the creep response is typically ignored and the dynamic modulus is taken as the ratio of the amplitude of the dynamic stress to the amplitude of the dynamic strain function. The tension/compression test on cylindrical specimen belongs to the homogeneous tests, i.e. It makes it possible to obtain directly the linear viscoelastic behavior through the complex modulus.

The principle of this test consists in soliciting in traction and compression a cylindrical specimen in a continuous way according to a sinusoidal signal (traction/compression) centered on zero and applied according to the axial direction of the specimen. In the case of a complex modulus test, a low number of cycles are applied to various frequencies.

\subsection{Material Characterization}

Complex modulus tests (Figure 1) were carried out using the Direct Traction - Compression (DTC) test on cylindrical samples according to Canadian and European standards (LC 26-700 and NF EN 12697-26, respectively).

Table 1.Some characteristics of HMA studied.

\begin{tabular}{|c|c|c|c|c|c|c|}
\hline \multirow[b]{2}{*}{ Mix composition } & \multicolumn{2}{|c|}{$\begin{array}{c}\text { Quartzit dense-dense } \\
\text { GDD }\end{array}$} & \multicolumn{2}{|c|}{$\begin{array}{c}\text { Quartzit dense-fine } \\
\text { GDF }\end{array}$} & \multicolumn{2}{|c|}{$\begin{array}{c}\text { Quarzit dense-coarse } \\
\text { GDC }\end{array}$} \\
\hline & $\begin{array}{c}\% \text { in } \\
\text { aggregate } \\
\text { mixture }\end{array}$ & $\%$ in HMA & $\begin{array}{l}\% \text { in aggregate } \\
\text { mixture }\end{array}$ & $\%$ in HMA & $\begin{array}{c}\% \text { in } \\
\text { aggregate } \\
\text { mixture }\end{array}$ & $\%$ in $\mathrm{HMA}$ \\
\hline Aggregate $0 / 3 \mathrm{~mm}$ & 58 & 55.05 & 65 & 61.62 & 49.4 & 49.4 \\
\hline Aggregate $3 / 8 \mathrm{~mm}$ & 12 & 11.39 & 20 & 18.96 & 23.75 & 23.75 \\
\hline $\begin{array}{l}\text { Aggregate } 8 / 14 \\
\mathrm{~mm}\end{array}$ & 30 & 28.48 & 15 & 14.22 & 21.85 & 21.85 \\
\hline $\begin{array}{c}\text { Bitumen } 35 / 50 \\
\text { or PG } 70 / 16 \\
\end{array}$ & 5.35 & 5.08 & 5.48 & 5.2 & 5 & 5 \\
\hline \multirow[b]{2}{*}{ Mix composition } & \multicolumn{2}{|c|}{$\begin{array}{c}\text { Basalt dense-dense } \\
\text { BDD }\end{array}$} & \multicolumn{2}{|c|}{$\begin{array}{l}\text { Basalt dense-fine } \\
\text { BDF }\end{array}$} & \multicolumn{2}{|c|}{$\begin{array}{c}\text { Basalt dense-coarse } \\
\text { BDC }\end{array}$} \\
\hline & $\begin{array}{c}\% \text { in } \\
\text { aggregate } \\
\text { mixture }\end{array}$ & $\%$ in HMA & $\begin{array}{l}\% \text { in aggregate } \\
\text { mixture }\end{array}$ & $\%$ in HMA & $\begin{array}{c}\% \text { in } \\
\text { aggregate } \\
\text { mixture }\end{array}$ & $\%$ in $\mathrm{HMA}$ \\
\hline Aggregate $0 / 3 \mathrm{~mm}$ & 50 & 47.53 & 60 & 56.94 & 32 & 30.53 \\
\hline Aggregate $3 / 8 \mathrm{~mm}$ & 15 & 14.26 & 20 & 18.98 & 31 & 29.58 \\
\hline Aggregate $8 / 16 \mathrm{~mm}$ & 35 & 33.27 & 20 & 18.98 & 37 & 35.3 \\
\hline $\begin{array}{c}\text { Bitumen } 35 / 50 \\
\text { or PG } 70 / 16 \\
\end{array}$ & 5.2 & 4.94 & 5.38 & 5.11 & 4.81 & 4.59 \\
\hline
\end{tabular}

Six mixtures (Table 1) were studied (BDC, BDD BDF, GDC, GDD and GDF). Each formula undergoes measurements at temperatures of $0{ }^{\circ} \mathrm{C}, 10^{\circ} \mathrm{C}, 20^{\circ} \mathrm{C}, 30^{\circ} \mathrm{C}, 40^{\circ} \mathrm{C}$ and $55^{\circ} \mathrm{C}$ and for each temperature the frequencies are $10 \mathrm{~Hz}, 5 \mathrm{~Hz}$,

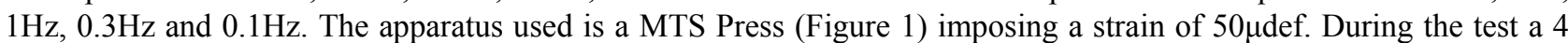
hours conditioning time is observed for each change in temperature so that it is homogeneous in the sample. The temperature changes are applied from the lowest to the highest. For each temperature, the stress is applied for different target frequencies from the highest to lowest with a limited number of cycles (Aidara, Ba \& Carter, 2015).

\subsection{Experimental Device and Testing Procedure}

The tests are carried out at the LCMB using a MTS hydraulic press (figure 1a). The press is controlled by an electronic system, series 8800 , and equipped with a nominal operating pressure of 210 bars, with a force cell of $50 \mathrm{kN}$. The operating software is the MTS Test Star ${ }^{\circledR}$ II . A servo-force control mode on the load cell or strain control mode on the average of three gauges can be used.

Preparation of the specimens according to standard LC 26-700 begins with the calculation of percentages of aggregates and bitumen (by formula) and compaction (of specimen of $30 \mathrm{~kg}$ ) by LCPC compactor shown in Figure $1 \mathrm{~b}$. Kneading and compaction temperatures are determined by the Brookfield viscosity test on the bitumen at $135{ }^{\circ} \mathrm{C}$ and $165{ }^{\circ} \mathrm{C}$. Before compacting the plates, HMA are conditioned for one hour in an oven.

The compacted plate must undergo a maturing ( 24 hours or more) before undergoing a core as shown in Figure 1c. The 
core was made according to a central plan so as to have four cylindrical samples per plate. The specimens in the center are more accurate than the other two to the edges. The plate compactor is selected by Lc26-700 method because it gives specimens with a uniform percentage of voids on the core plan. A study of the distribution of voids inside samples prepared using Gyratory Compactor (GC) showed that voids are not uniformly distributed (Doucet \& Auger, 2012), and changes in interstitial voids in the samples was unacceptable.

Once the specimens are cored (Figure 1c), they undergo a sawing and smoothing to have relatively consistent size specimens with the specifications of the test method $(75 \mathrm{~mm}( \pm 1)$ diameter and $150 \mathrm{~mm}( \pm 2)$ in height $)$.

On each specimen, measurements are performed to determine the specific gravity (hydrostatic weighing method) and bulk specific gravity (volumetric method) to derive the percentage voids. These methods are shown in Figure 1.d.
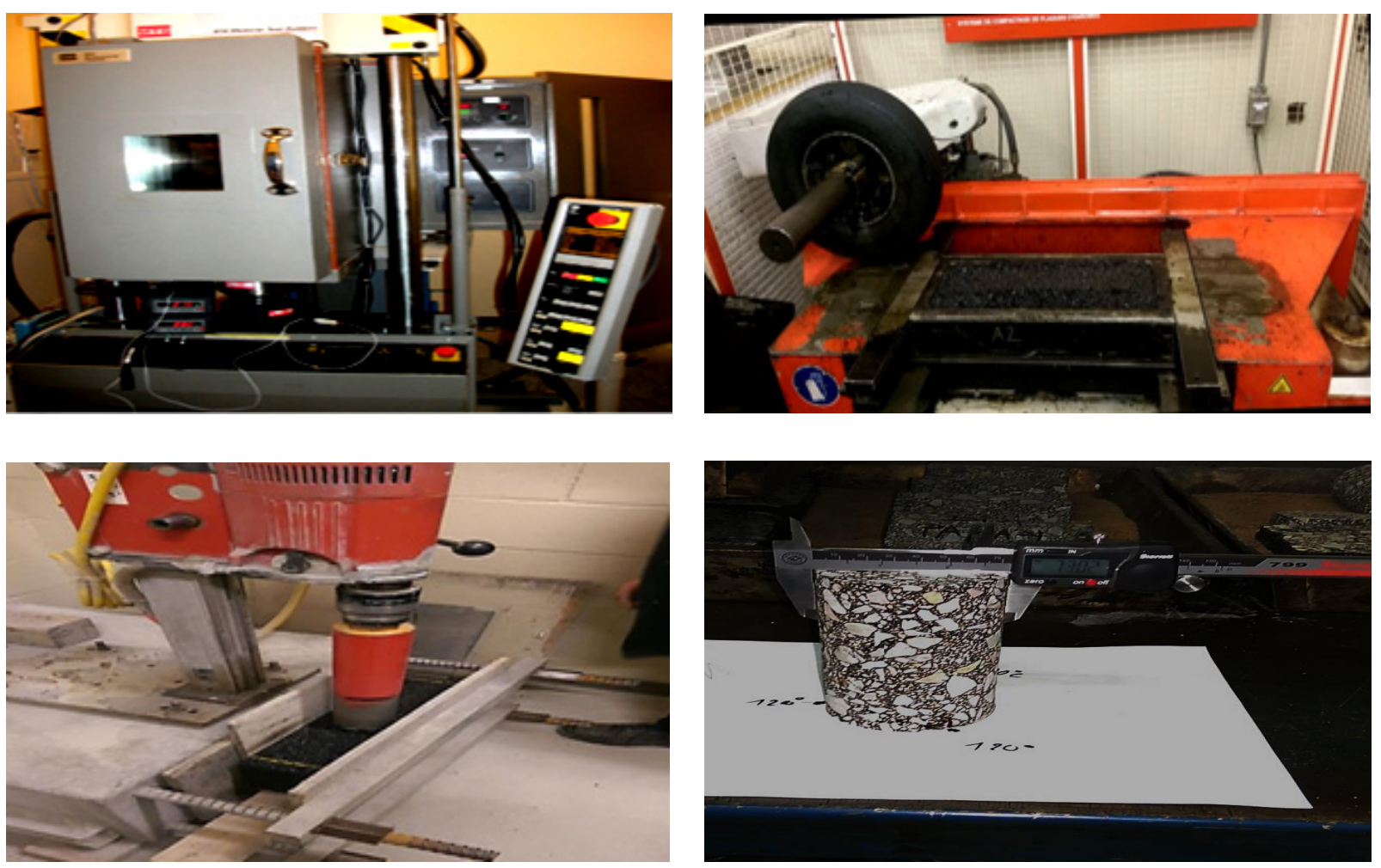

Figure 1. a) LCMB Experimental device; b) LCPC plate compactor (LCMB); c) Plate coring machine; d) Dimensions measurement of specimens

The samples undergo a maturing of 2 weeks minimum. For this study the specimens underwent a maturing of one month anchored in sand at room temperature as shown in Figure 2a.

The initial step of setting up a traction-compression test is fitting helmets centered on both edges of the specimen to be tested. Helmets are the intermediate element that links the specimen to the press by the rings of anchor. (Touhara, 2012) states that during the complex modulus test, proper centering of the specimen is essential to avoid bending it. Helmets are bonded to the test piece with epoxy and clamped on the clamping bench for a minimum time of 4 hours as shown in Figure $2 b$. 

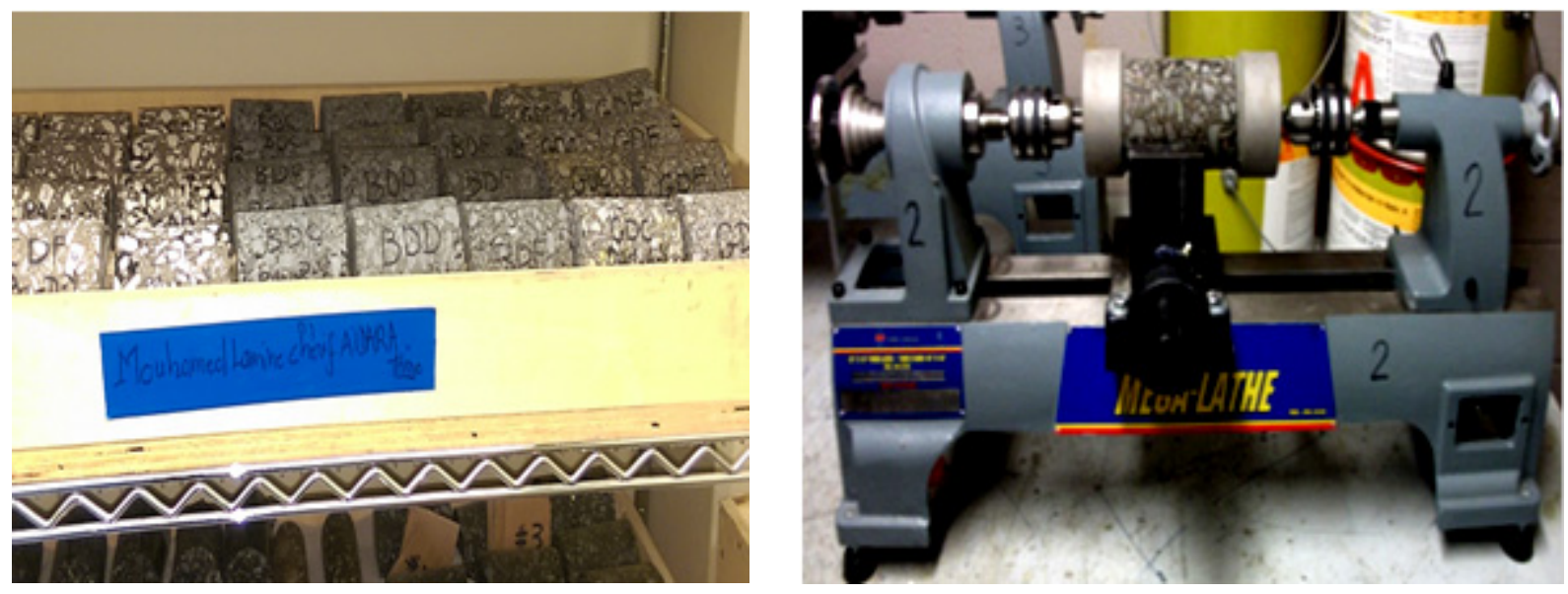

Figure 2. a) Maturing of specimen before TCD test (LCMB); b) LCMB Adhering and drying helmets by epoxy glue (Touhara, 2012)

After adhering and drying epoxy on the test specimens, three extensometers of $50 \mathrm{~mm}$ length are mounted on the specimens at distant angles of $120^{\circ}$. The strain gauges are interconnected by six springs of the same caliber as shown in Figure 3. The assembly is then mounted on the press.
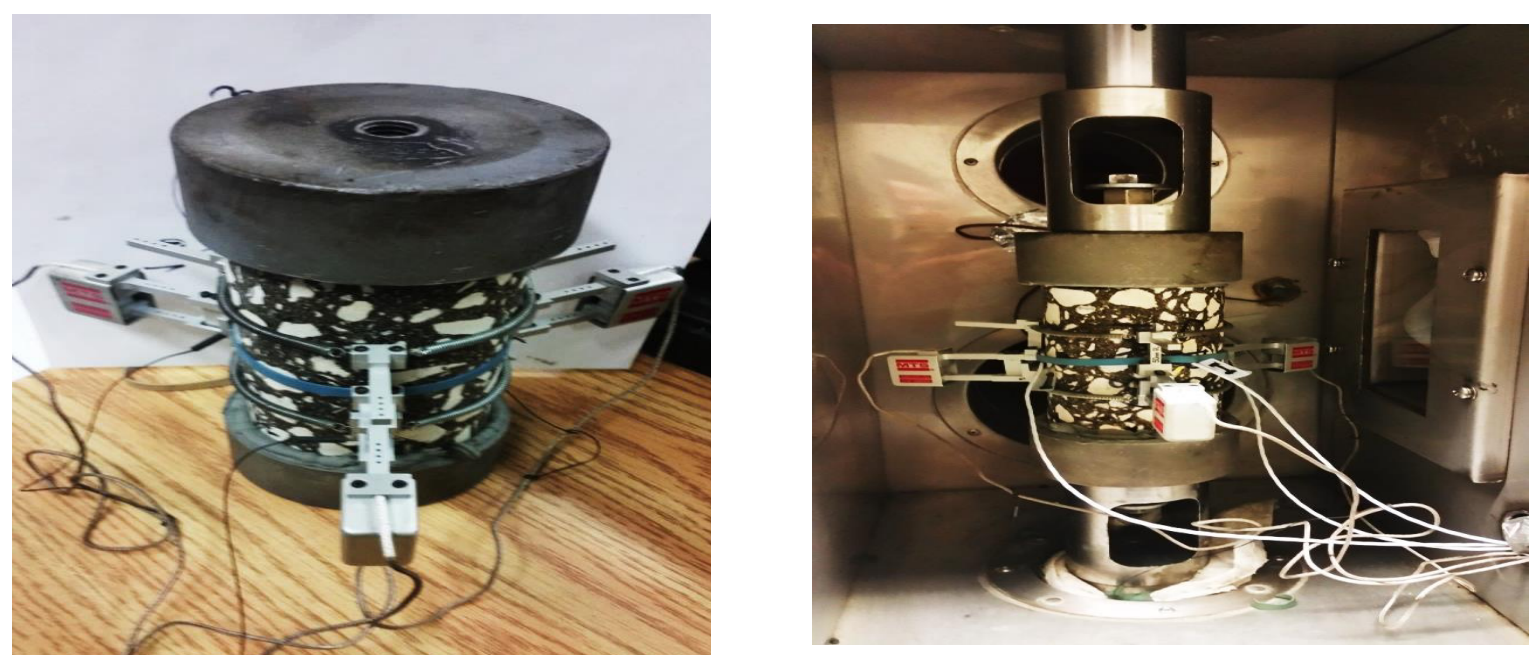

Figure 3. Installation of gauges and installation in the press of a test piece

The final stage of the implementation of the traction-compression test is the conditioning of the temperature. Indeed for the trials in LCMB, temperature sensors are placed on the surface of the specimen to measure the thermal evolution of the surface of the specimen being tested. Before starting the test, the force applied to the specimen is zero and 4 hours conditioning time is observed to reach the target temperature within the specimen to be tested.

\subsection{Data Acquisition System}

Upon acquisition, the sampling frequency is determined according to the stress frequency to obtain 100 acquisition points per cycle, and this for all used sensors (load cell, two temperature probes one the surface one in the room, three extensometers, moving of the jack). Each acquisition consists in recording two consecutive cycles of solicitation and thus sampling 200 points of measurements for each sensor. The choice of two cycles allows a more precise calculation of the amplitude and dephasing of the signal. The system of acquisition allows the recording of the following values (Touhara, 2012):

- The time and the applied cycle number;

- The force (F) exerted on the test piece;

- The movement of the piston of the press;

- axial strain $(\varepsilon)$ of 3 gauges;

- The temperature of the surface of the specimen; 
- Enclosure temperature.

\section{Results and Analyses}

Table 2. Dynamic modulus test results for BDC mix / LC 26700 / NF EN 12697-26.

\begin{tabular}{cccccc}
\hline Temperature & Frequency & $\left|\mathbf{E}^{*}\right|$ & & $\mathbf{E}_{\mathbf{1}}$ & $\mathbf{E}_{\mathbf{2}}$ \\
\hline${ }^{\circ} \mathbf{C}$ & $\mathbf{H z}$ & $\mathbf{M P a}$ & $\mathbf{(}^{\circ} \mathbf{)}$ & $\mathbf{M P a}$ & $\mathbf{M P a}$ \\
0.1 & 10.05 & 14105 & 7.7 & 13977 & 1895 \\
0.2 & 3.02 & 12592 & 9.1 & 12432 & 1997 \\
0.2 & 1.00 & 11146 & 10.5 & 10959 & 2033 \\
0.1 & 0.30 & 9587 & 12.7 & 9353 & 2103 \\
0.2 & 0.10 & 8063 & 15.3 & 7778 & 2127 \\
9.8 & 10.04 & 9872 & 12.6 & 9635 & 2147 \\
9.8 & 3.01 & 8264 & 14.9 & 7985 & 2131 \\
9.8 & 1.01 & 6724 & 18.1 & 6391 & 2089 \\
9.8 & 0.30 & 5146 & 22.2 & 4765 & 1943 \\
9.8 & 0.10 & 3887 & 26.3 & 3484 & 1723 \\
20.3 & 10.03 & 5316 & 22.3 & 4919 & 2014 \\
20.3 & 3.01 & 3874 & 26.9 & 3454 & 1754 \\
20.3 & 1.00 & 2722 & 31.6 & 2318 & 1426 \\
20.2 & 0.30 & 1756 & 36.6 & 1410 & 1047 \\
20.1 & 0.10 & 1122 & 40.5 & 854 & 729 \\
30.2 & 10.02 & 2422 & 34.3 & 2001 & 1363 \\
30.2 & 3.01 & 1515 & 38.8 & 1180 & 950 \\
30.2 & 1.01 & 940 & 41.8 & 701 & 627 \\
30.2 & 0.30 & 550 & 42.4 & 406 & 371 \\
30.2 & 0.10 & 338 & 40.9 & 255 & 221 \\
40.5 & 10.09 & 835 & 44.1 & 600 & 581 \\
40.5 & 3.02 & 484 & 43.5 & 351 & 333 \\
40.5 & 1.00 & 302 & 40.2 & 231 & 195 \\
40.5 & 0.30 & 194 & 34.8 & 159 & 110 \\
40.5 & 0.10 & 142 & 29.5 & 124 & 70 \\
55.4 & 10.09 & 223 & 37.7 & 177 & 137 \\
55.4 & 3.02 & 162 & 29.1 & 141 & 79 \\
55.4 & 1.01 & 133 & 22.4 & 123 & 51 \\
55.3 & 0.30 & 114 & 17.6 & 108 & 34 \\
55.4 & 0.10 & 103 & 14.7 & 100 & 26 \\
\hline
\end{tabular}

Table 3. Dynamic modulus test results for GDD mix / LC 26700/ NF EN 12697-26.

\begin{tabular}{cccccc}
\hline Temperature & Frequency & $\left|\mathbf{E}^{*}\right|$ & & $\mathbf{E}_{\mathbf{1}}$ & $\mathbf{E}_{\mathbf{2}}$ \\
\hline${ }^{\circ} \mathbf{C}$ & $\mathbf{H z}$ & $\mathbf{M P a}$ & $\mathbf{(}^{\circ} \mathbf{)}$ & $\mathbf{M P a}$ & $\mathbf{M P a}$ \\
0.1 & 10.04 & 18017 & 6.7 & 17894 & 2098 \\
0.1 & 3.01 & 16194 & 7.7 & 16046 & 2181 \\
0.1 & 1.01 & 14674 & 10.3 & 14439 & 2614 \\
0.2 & 0.30 & 12613 & 12.5 & 12316 & 2720 \\
0.2 & 0.10 & 10668 & 14.9 & 10309 & 2742 \\
10.0 & 10.04 & 12838 & 12.5 & 12535 & 2772 \\
10.0 & 3.02 & 10434 & 15.8 & 10041 & 2834 \\
10.0 & 1.00 & 8540 & 19.6 & 8046 & 2863 \\
10.0 & 0.30 & 6391 & 24.8 & 5802 & 2679 \\
10.0 & 0.10 & 4622 & 30.5 & 3983 & 2345 \\
20.1 & 10.04 & 6611 & 24.4 & 6018 & 2736 \\
20.1 & 3.01 & 4593 & 30.4 & 3959 & 2327 \\
20.1 & 1.00 & 3015 & 37.7 & 2384 & 1846 \\
20.1 & 0.30 & 1715 & 45.4 & 1204 & 1221 \\
20.1 & 0.10 & 947 & 51.6 & 588 & 741 \\
30.1 & 10.06 & 2563 & 41.4 & 1924 & 1694 \\
30.1 & 3.02 & 1410 & 48.5 & 935 & 1055 \\
30.0 & 1.00 & 750 & 54.2 & 438 & 608 \\
30.0 & 0.30 & 349 & 58.4 & 183 & 297 \\
30.0 & 0.10 & 173 & 60.3 & 86 & 151 \\
40.2 & 10.05 & 690 & 56.5 & 381 & 575 \\
40.1 & 3.03 & 325 & 58.5 & 170 & 277 \\
40.1 & 1.00 & 161 & 57.5 & 87 & 136 \\
40.2 & 0.30 & 80 & 53.1 & 48 & 64 \\
40.1 & 0.10 & 46 & 45.9 & 32 & 33 \\
55.0 & 10.00 & 120 & 51.4 & 75 & 94 \\
55.0 & 3.00 & 70 & 39.4 & 54 & 45 \\
55.0 & 1.00 & 49 & 28.6 & 43 & 24 \\
55.0 & 0.30 & 39 & 20.5 & 37 & 14 \\
55.0 & 0.10 & 34 & 15.8 & 33 & 9 \\
\hline
\end{tabular}

The results of measurements of the dynamic modulus tests on asphalt mixes studied in six different frequencies and 
temperature are presented in table 2 and table 3 (for example BDC and GDC). The comparison of the results in Tables 2 and 3 shows that the quartzite HMA and the basalt HMA are well suited to the complex modulus test. The dynamic modulus values obtained are consistent with the specifications of NF EN 13108-1 standard. The tables also show the best performance for the quartzite, but that is not the case for all bituminous mixtures studied.

\subsection{Presentation of Results from Complex Modulus Testing}

The results of the complexmodulus E* are generally represented in the complex Cole-Cole plan or in Black diagrams. Results can also be represented as isothermal curve or as isochronal curve. The isothermal curves show the evolution of the absolute value of the complex modulus $\left|\mathrm{E}^{*}\right|$ as function of the frequency for each of the test temperatures, generally in log-log coordinates. The slope of the isotherms allows estimating the kinetics susceptibility of bituminous material, that is to say, the variation of modulus with the speed of the solicitation. Figures 4 to 6 show the isotherms $\left|E^{*}\right|$ of the materials tested.
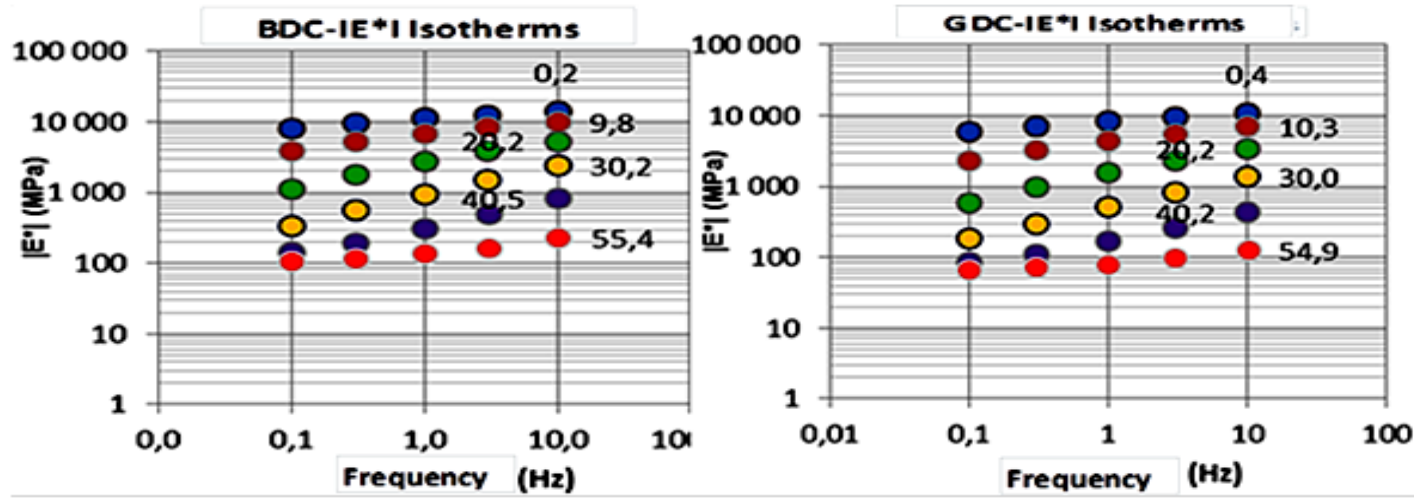

Figure 4. Isotherms for BDC mix (left) and GDC mix (right)
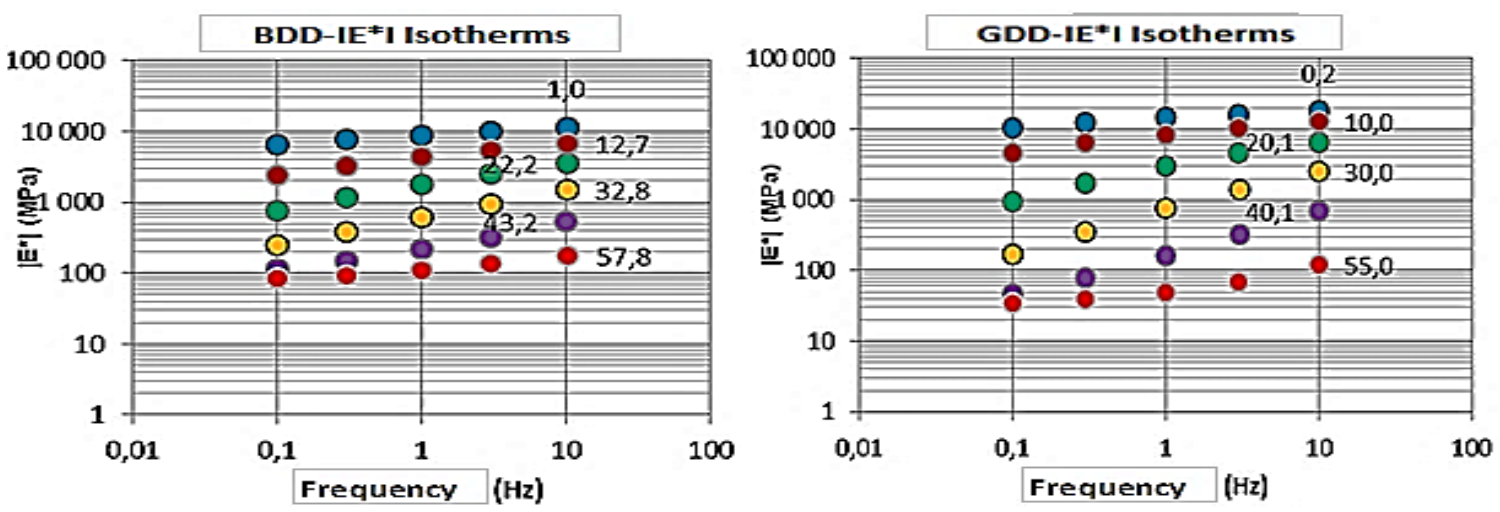

Figure 5. Isotherms for BDD mix (left) and GDD mix (right)
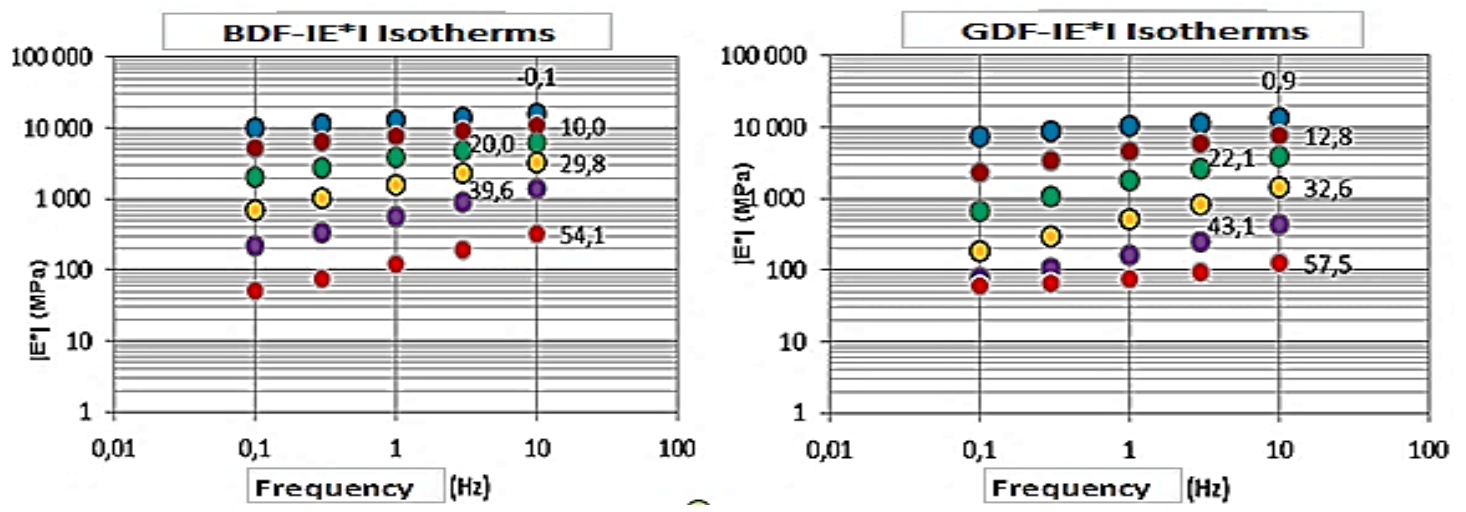

Figure 6. Isotherms for BDF mix (left) and GDF mix (right) 
The representation in the Cole-Cole diagram is to bring the real part of the complex modulus $\mathrm{E}_{1}$ in $\mathrm{X}$-coordinate and the imaginary part $\mathrm{E}_{2}$ in Y-coordinate. The resulting curve is characteristic of each HMA studied. Some models are calibrated from the Cole-Cole representation. The Figures 7 to 9 shows the results of $\mathrm{E}^{*}$ of bituminous mixes of the study at different frequencies and temperatures in the complex plan of Cole-Cole, where $E_{2}$ is plotted as function of $E_{1}$.
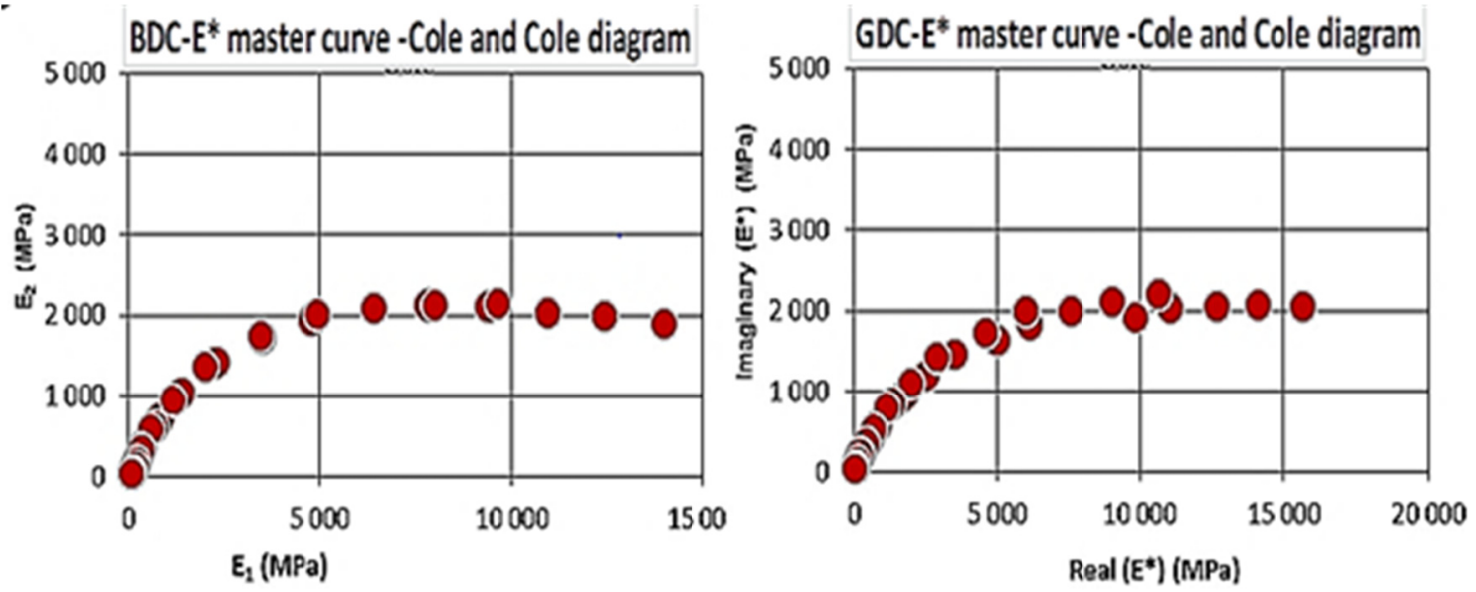

Figure 7. Representation of $\mathrm{E}^{*}$ in the Cole-Cole diagram for BDC mix (left) and GDC mix (right)
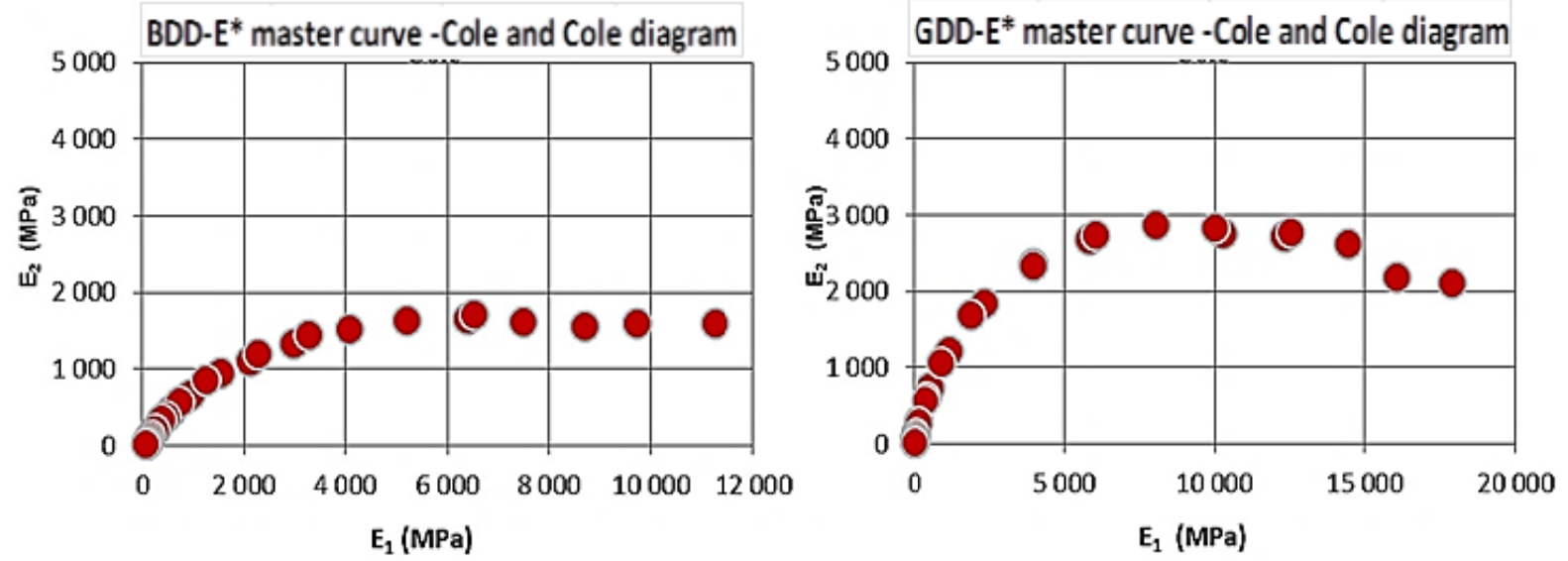

Figure 8. Representation of $\mathrm{E}^{*}$ in the Cole-Cole diagram for BDD mix (left) and GDD mix (right)
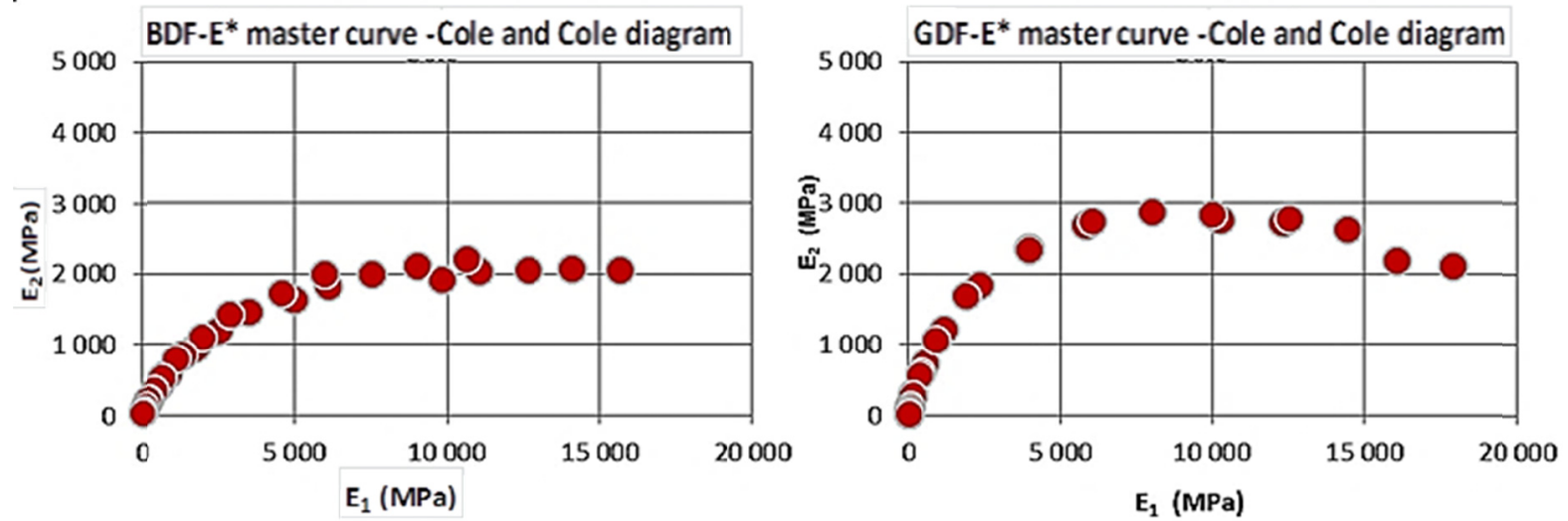

Figure 9. Representation of $\mathrm{E}^{*}$ in the Cole-Cole plan for BDF mix (left) and GDF mix (right)

All curves of $\mathrm{E}^{*}$ represented in the Cole-Cole diagram shows a uniqueness (approximation) stronger in some than in others. However the studied HMA can be considered thermorheologically simple and that the principle of time-temperature superposition can be applied it is necessary that uniqueness of the curves is also checked in the Black diagram (Doucet \& Auger, 2009). Indeed this uniqueness is shown by Figures10 to 12 illustrating the representation of $\mathrm{E}^{*}$ in the Black diagram. 

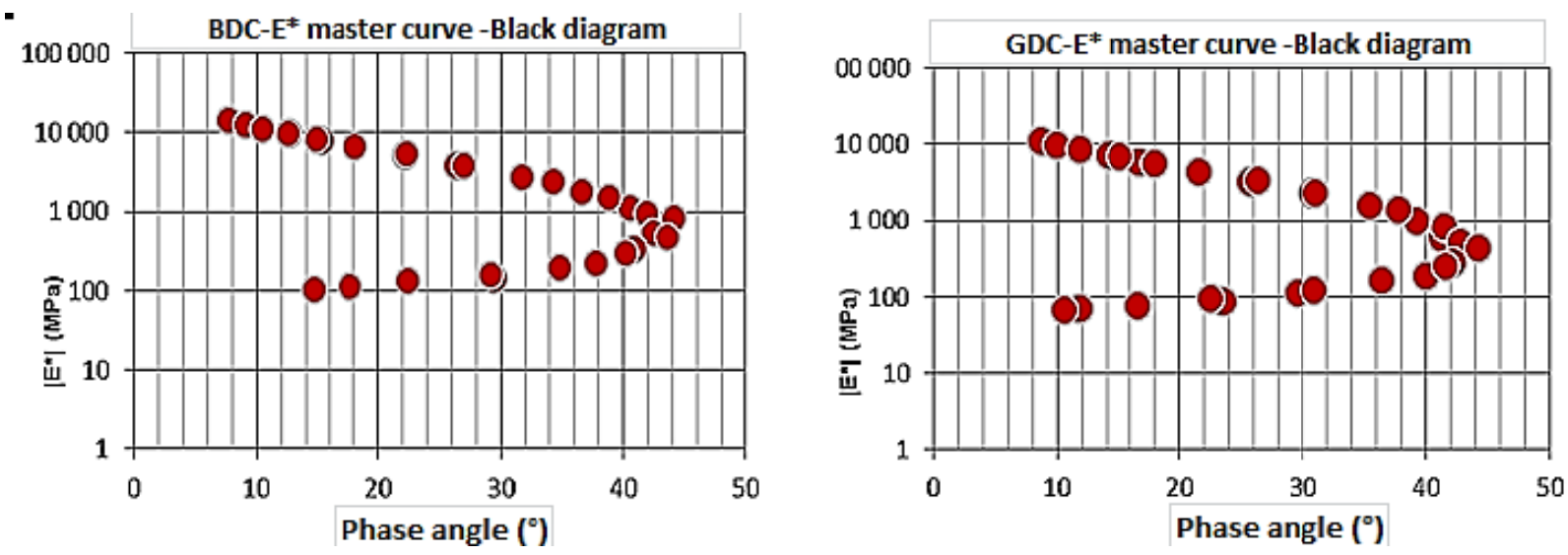

Figure 10. Black diagram for BDC mix (left) and GDC mix (right)
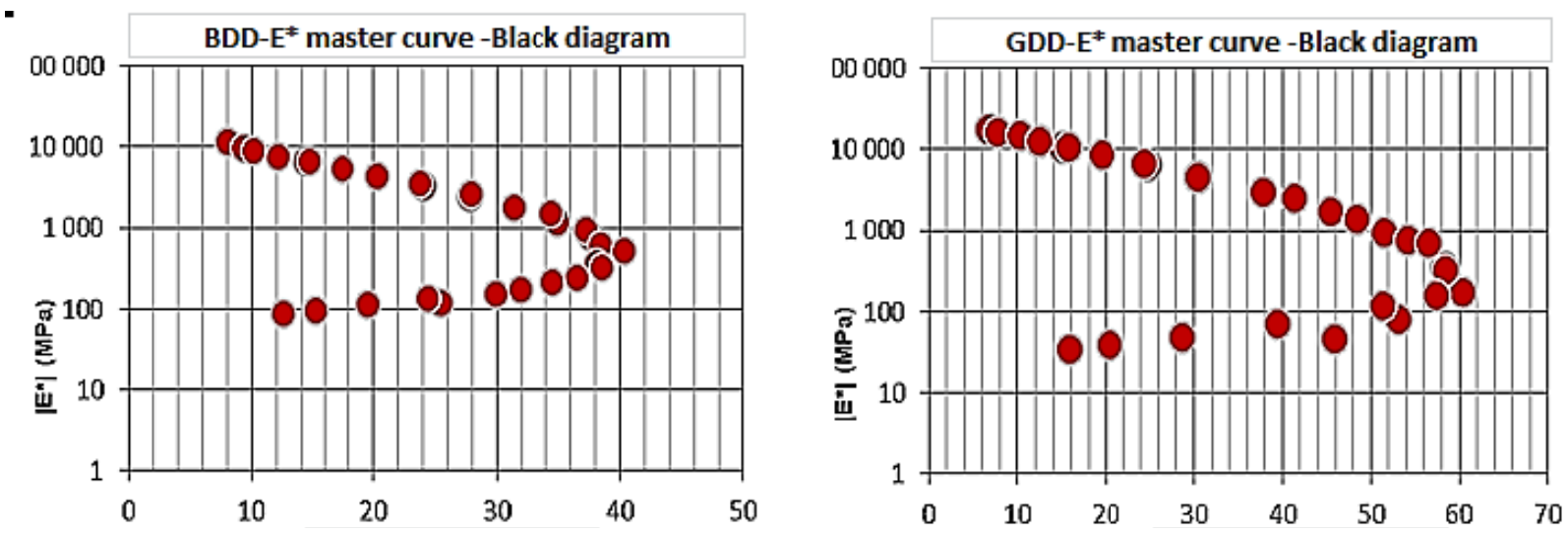

Figure 11. Black diagram for BDD mix (left) and GDD mix (right)
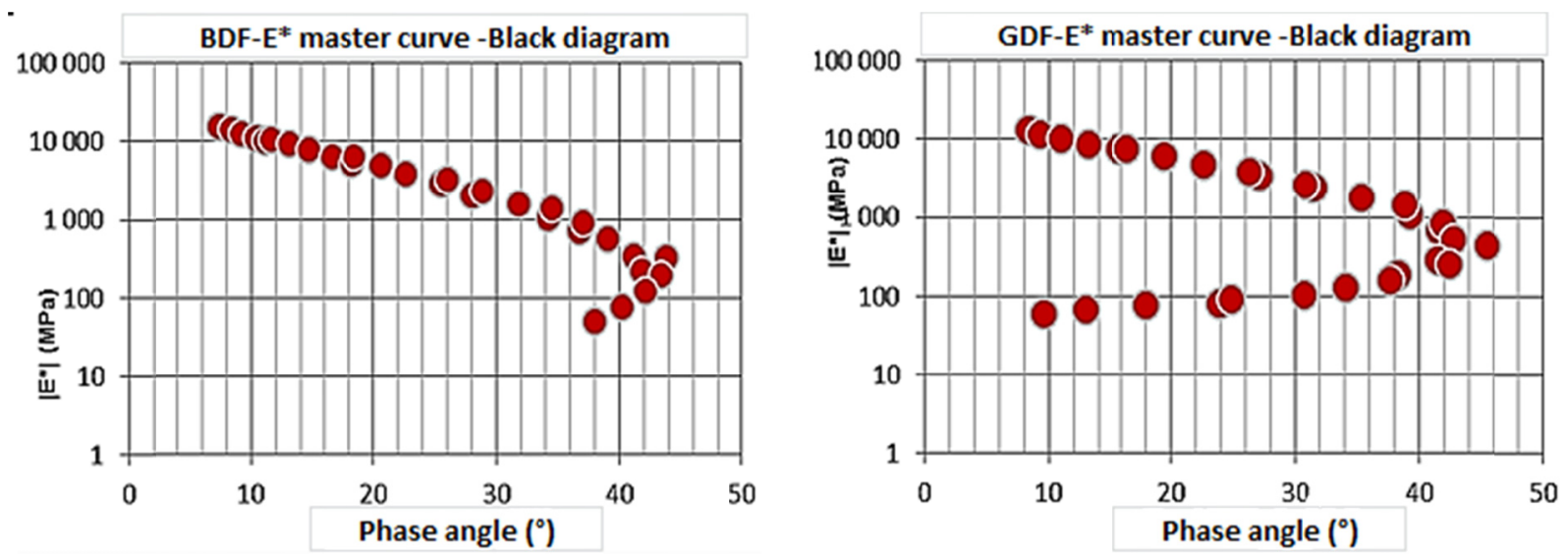

Figure 12. Black diagram for BDF mix (left) and GDF mix (right)

The principle of time-temperature equivalence argues that a same value of $\mathrm{E}^{*}$ can be achieved with different frequency and temperature couples, which allow to determine an equivalent frequency (reduced) for a ref-erence temperature. Thus, the isotherms of $\left|E^{*}\right|$ and $\varphi$ can be translated with respect to the frequency axis to be superimposed in the form of a master curve at a reference temperature (Di Benedetto \& Corté, 2005). The master curve provides the values of $\left|E^{*}\right|$ at frequencies unattainable through experimentation. A translation of isotherm is possible by the use of the translation coefficient $\mathrm{a}(\mathrm{T})$, with respect to the isotherm of reference. Figures 13 to 15 present the master curves of asphalt mixtures investigated by William Landel Ferry (WLF) law (Raymond \& Such, 2003). 

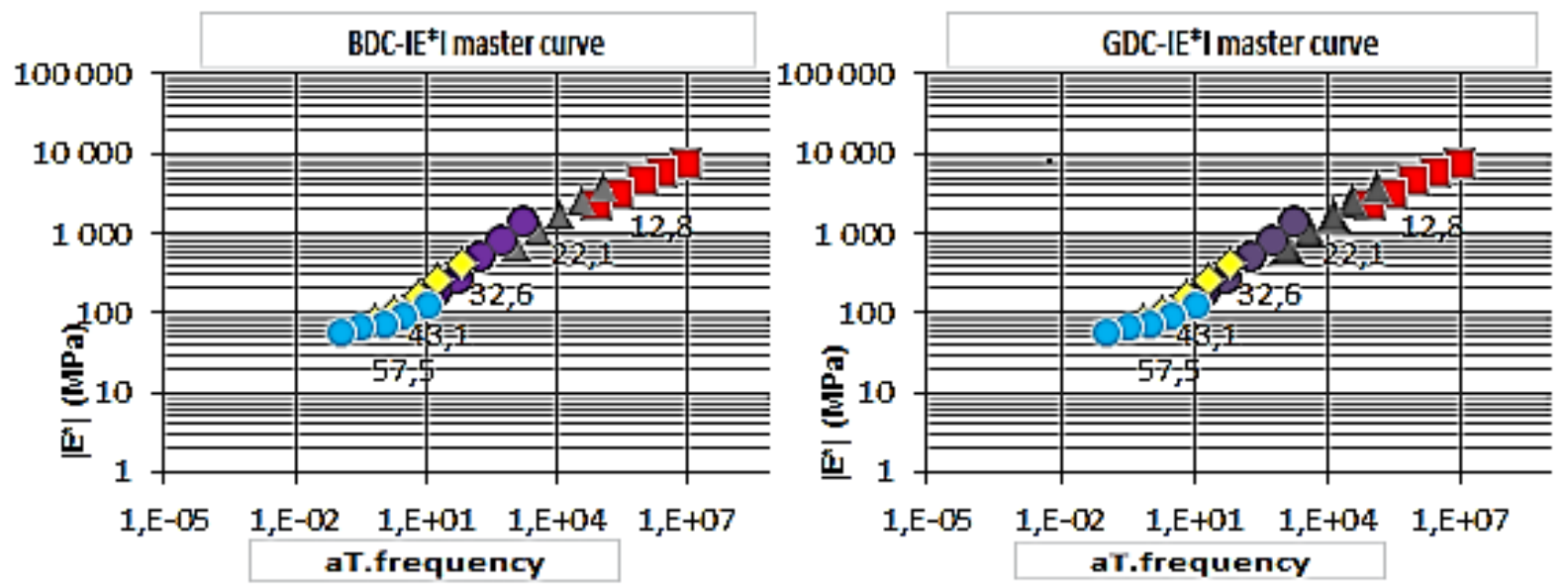

Figure 13. Master curve for BDC mix (left) and GDC mix (right) atTref $=10^{\circ} \mathrm{C}$
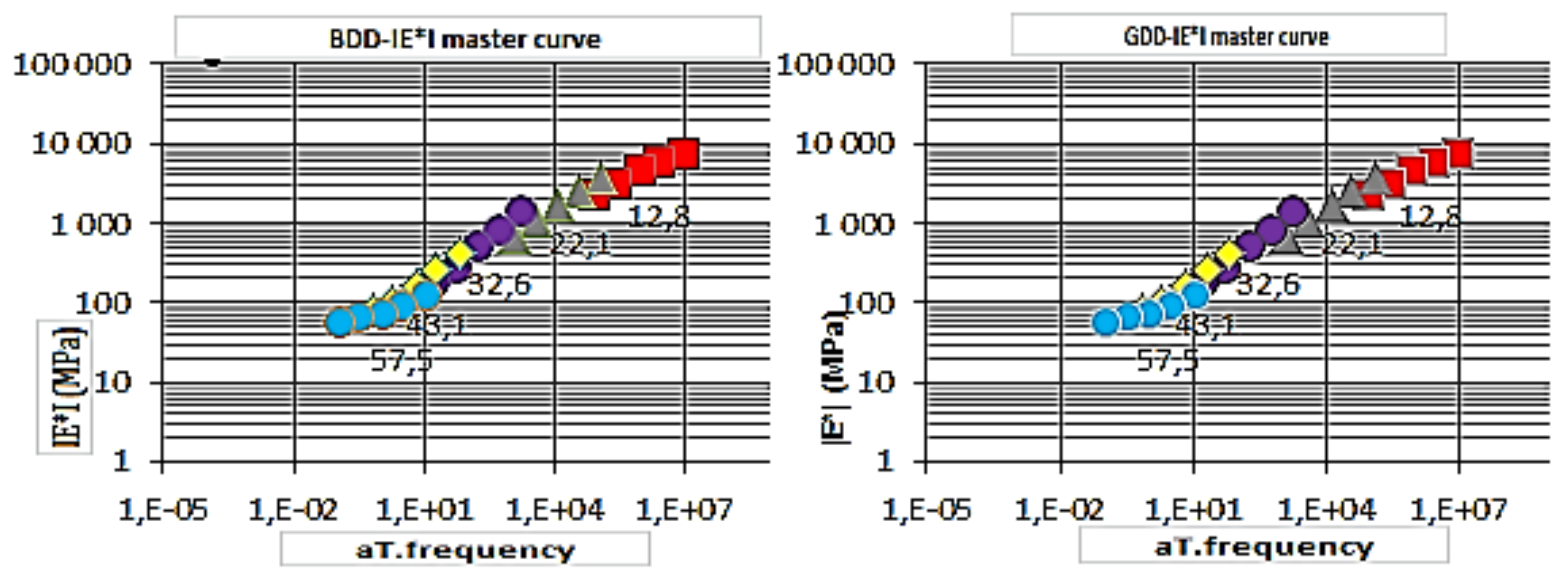

Figure 14. Master curve for BDD mix (left) and GDD mix (right) atTref $=10^{\circ} \mathrm{C}$
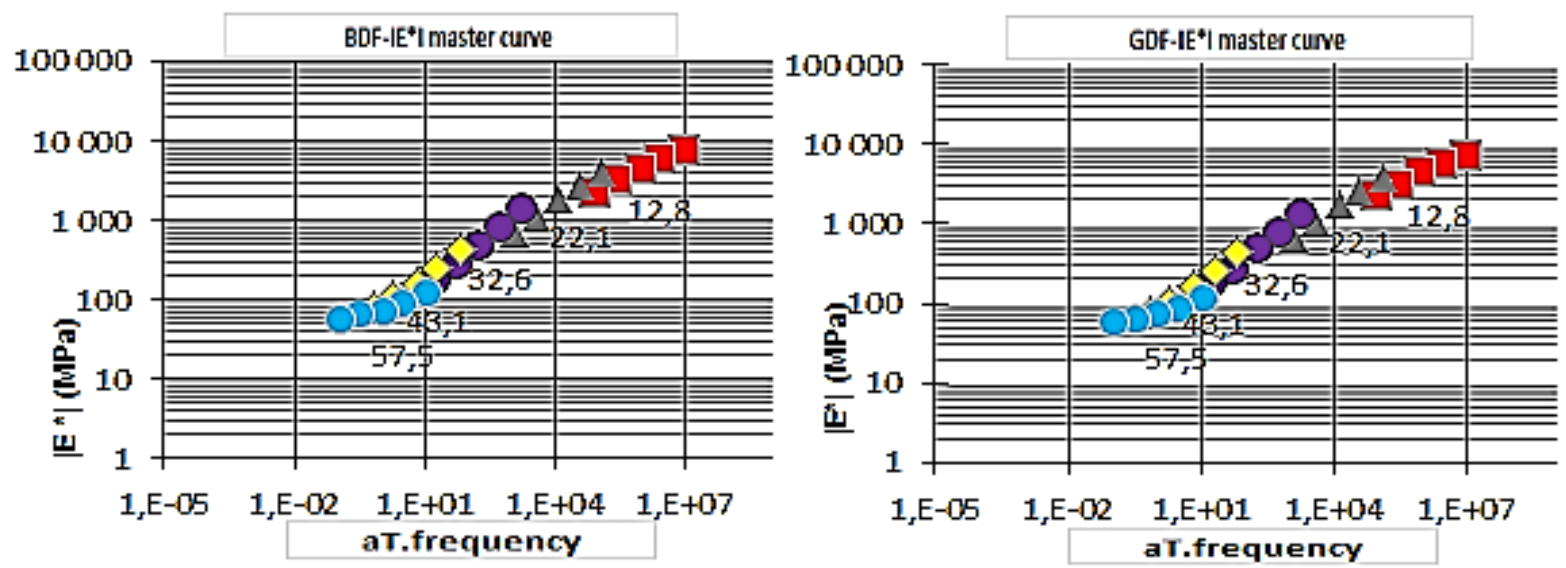

Figure 15. Master curve for BDF mix (left) and GDF mix (right) atTref $=10^{\circ} \mathrm{C}$

\subsection{Modeling $\left|E^{*}\right|$ Using the Witczak Sgmoidal Model}

In the Mechanistic-Empirical Design method (NCHRP, 2014), the master curve can be modeled by a sigmoidal function and used in the Mechanistic-Empirical Pavement Design Guide (M-EPDG). The sigmoidal function is described in the form of the equation (1):

$$
\log \left(E^{*}\right)=\delta+\frac{\alpha}{1+e^{\beta+\gamma\left(\log t_{r}\right)}}
$$

Where:

$$
\begin{aligned}
& t_{r}=\text { reduced time of loading at the reference temperature, } \\
& \delta=\text { minimum value of } E^{*} ;
\end{aligned}
$$




\section{$\delta+\alpha=$ Maximum value of $\mathrm{E} *$;}

$\beta, \gamma=$ parameters describing the shape of the sigmoidal function.

In this modeling the shift factor a(T) describe the temperature dependency of the modulus. Equation (2) gives the general form of the shift factors:

$$
a(T)=t / t_{r}
$$

Where:

a $(\mathrm{T})=$ shift factor as function of temperature;

$\mathrm{t}=$ time of loading at the reference temperature ;

$\operatorname{tr}=$ time of loading at the reference temperature

$\mathrm{T}=$ temperature of interest (reference).

For more precision a polynomial relation of second degrees can be used. It binds log a(Ti) to the temperature in degrees Fahrenheit (Equation 3).

$$
\log a(T i)=a T_{i}^{2}+b T i+c
$$

Where:

a $(\mathrm{T})=$ shift factor as function of temperature;

$\mathrm{a}, \mathrm{b}$ and $\mathrm{c}=$ coefficient of the second-degree polynomial.

The time-temperature superposition is performed by solving simultaneously for four coefficients of the sigmoidal function $(\delta, \alpha, \beta$, and $\gamma)$ as described in equation (1) and the three coefficients of the second order polynomial (a, b, and c) as described in equation (3). A nonlinear optimization program to simultaneously solve these seven parameters is used for the development of basic curves.

\subsection{Adjustment for Determining Parameters of Witczak Sigmoidal Model}

It consists with a fitting of the values of $\left|E^{*}\right|$ measured with the values of $\left|E^{*}\right|$ predicted with the model by var-iation of the model parameters until the superposition of the two master curves. The optimal adjustment is ob-tained by minimizing the average prediction error (RMSE).

Table 4. Constants of calibrated sigmoidal Witczak model

\begin{tabular}{ccccccc}
\hline \multirow{2}{*}{ HMA mix } & \multicolumn{7}{c}{ Witczak sigmoïdal model parameters } \\
\cline { 2 - 6 } & $\boldsymbol{\delta}$ & $\boldsymbol{\alpha}$ & $\boldsymbol{\beta}$ & $\boldsymbol{\gamma}$ & $\mathbf{C}$ & RMSE \\
\hline GDC & 3.7454 & 2.4411 & -1.7701 & 0.7234 & 1.2503 & 0.039 \\
BDC & 3.9297 & 2.3468 & -2.0547 & 0.7425 & 1.2583 & 0.034 \\
GDD & 3.4002 & 2.9684 & -2.3947 & 0.8397 & 1.2108 & 0.030 \\
BDD & 3.8344 & 2.3897 & -1.6557 & 0.6592 & 1.2647 & 0.047 \\
GDF & 3.6706 & 2.6124 & -1.6794 & 0.6543 & 1.3285 & 0.045 \\
BDF & 1.8512 & 4.5718 & -2.4792 & 0.3913 & 1.4951 & 0.020 \\
\hline
\end{tabular}

Table 4 summarizes the model parameters determined for the six studied mixtures. Figures 16 to 18 show the modeled master curves from the sigmoidal model Witczak.
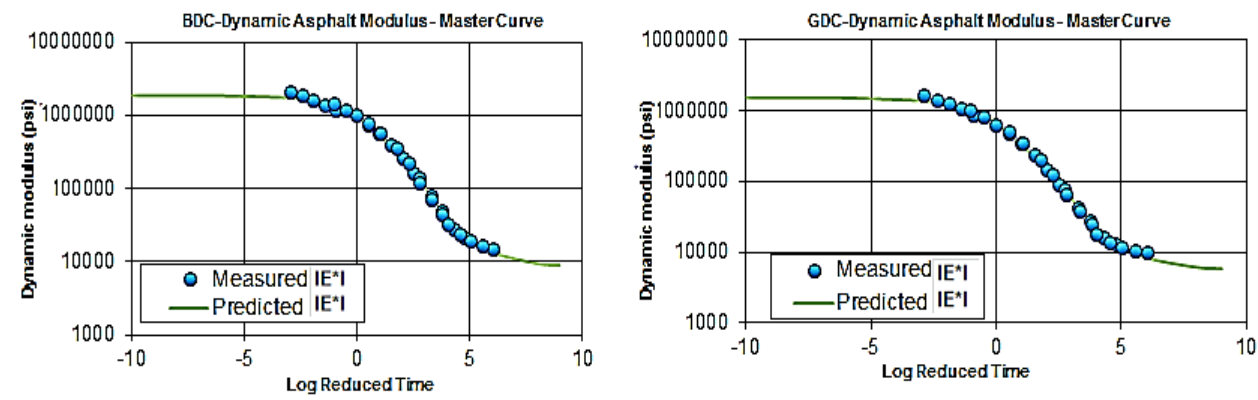

Figure 16. $\left|\mathrm{E}^{*}\right|$ Master curves for $\mathrm{BDC}$ and $\mathrm{GDC}$ at $\operatorname{Tref}=10^{\circ} \mathrm{C}$ 

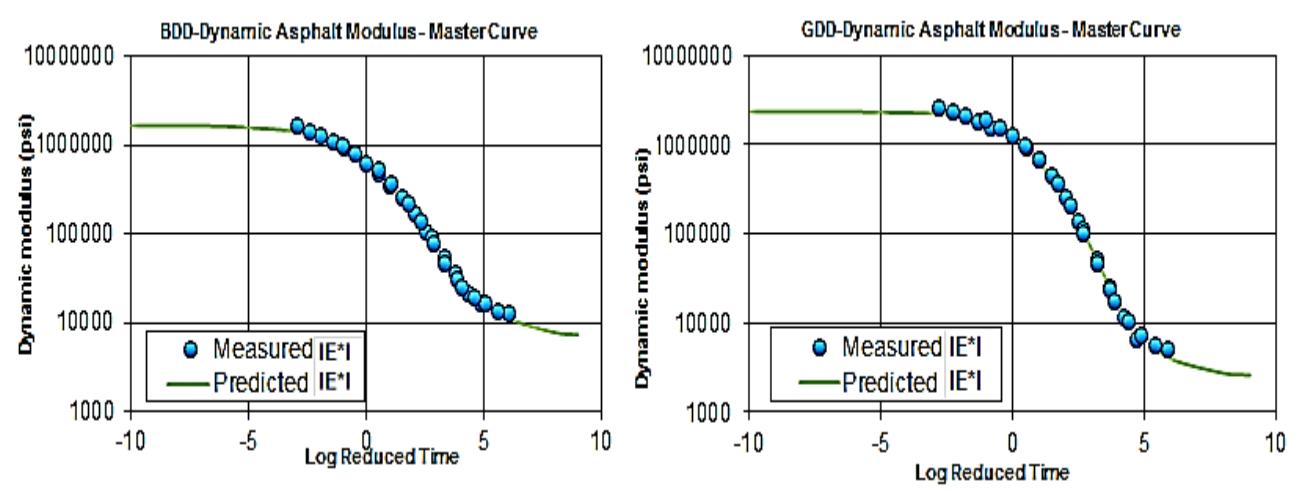

Figure 17. $\left|\mathrm{E}^{*}\right|$ Master curves for BDD and GDD at Tref $=10^{\circ} \mathrm{C}$
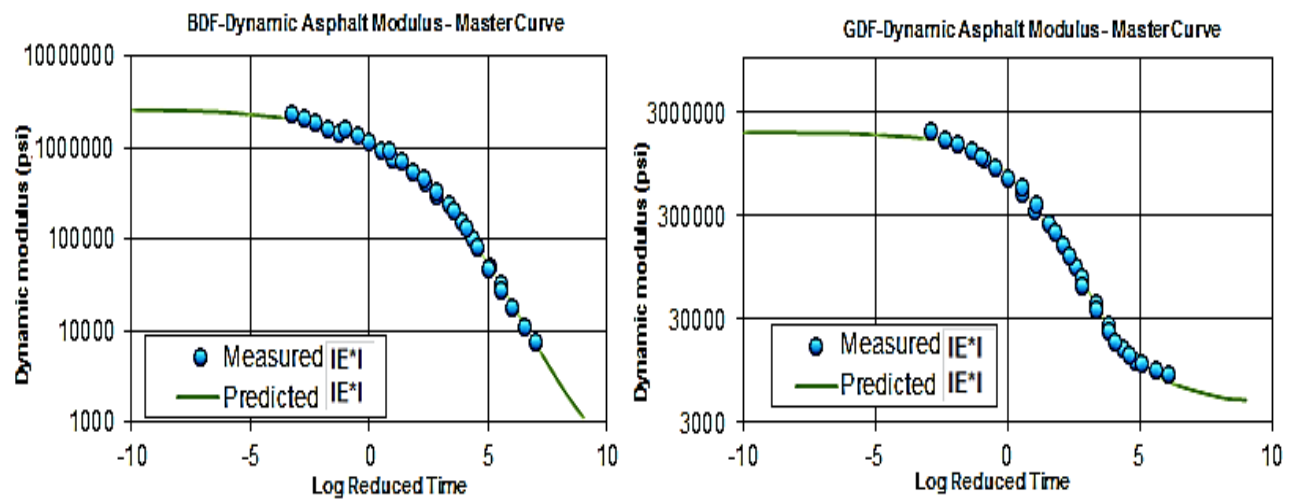

Figure 18. $\left|\mathrm{E}^{*}\right|$ Master curves for BDF and GDF at $\operatorname{Tref}=10^{\circ} \mathrm{C}$

The sigmoidal model provides good modeling of $\left|\mathrm{E}^{*}\right|$ for Diack basalt and Bakel quartzite HMA (RMSE $\left.<0,05\right)$. The correlation using STATISTICA between the predicted modulus values and the measured modulus values shows that the sigmoidal model has a good correlation with $\mathrm{r}^{2}=0,99$ at $\mathrm{p}=0,00$ (Figure 19).

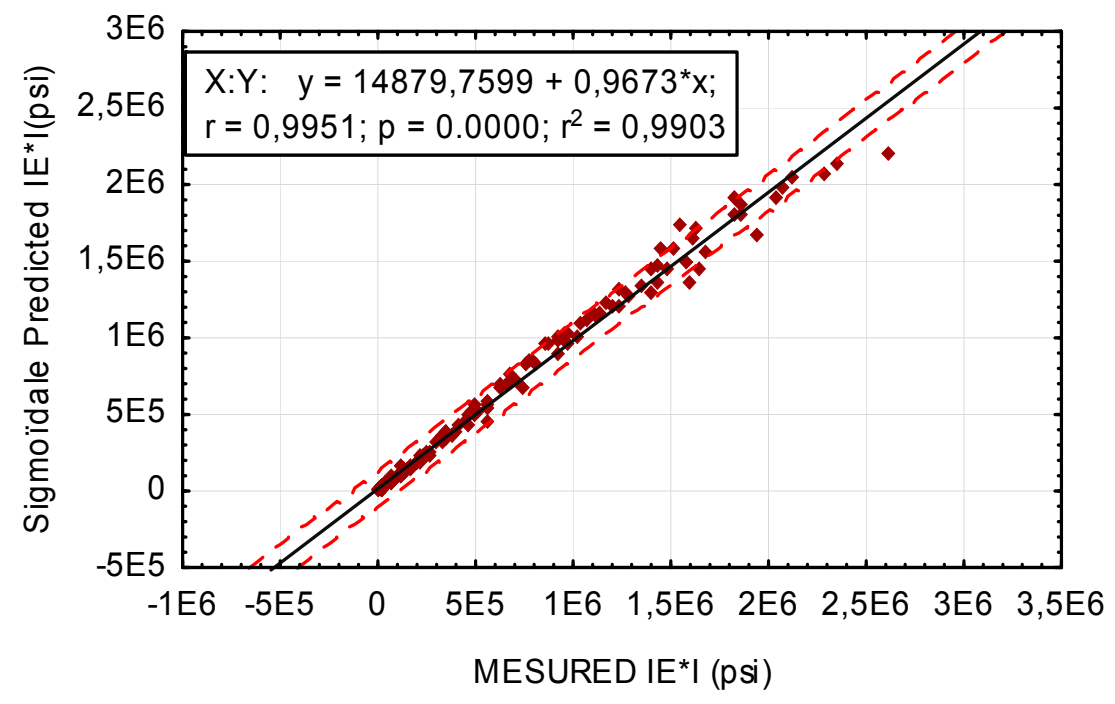

Figure 19. Correlation beetween predicted $\left|\mathrm{E}^{*}\right|$ and mesured $\left|\mathrm{E}^{*}\right|$ 


\section{Conclusion}

LC 26-700 test procedure does apply to asphalt concretes mix designed with aggregates basalt of Diack and quartzite of Bakel. It is partially overlaps with AFNOR (EN 12-697) and AASHTO TP 62-7 tests methods. During the preparation of specimens for the complex modulus test, the plate compactor is preferable to the shear gyratory press, as it gives the specimens to uniform percentage on the empty core plan. The studied asphalt concretes (BDC BDD BDF, GDC, GDD, and GDF) are thermorhéologically simple, because they have a good enough uniqueness of their master curve of the complex modulus $\mathrm{E}^{*}$ in the Cole and Cole plane and the Black Space. The sigmoidal Witczak model have good modeling studied coated module. However, the sigmoidal model Witczak appears to have better accuracy. The influence of particle size is reflected by the influence of the percentage of voids in the bituminous mixture. Indeed it greatly influences the complex modulus of the studied mixtures.

\section{Acknowledgements}

The authors would like to acknowledge Professor Meissa FALL (RIP) for his guidance and valuable input in this research project; and the "Mapathé NDIOUCK Compagny" for supporting the high price shipping of aggregates from Senegal to Canada.

\section{References}

[AASHTO TP 62-07. Standard Method of Test for Determining Dynamic Modulus of Hot Mix Asphalt HMA)

[AFNOR (2012). NF EN 12697-26, Asphalt Mixtures, Test Method for asphalt Mixtures. Partie 26, Modulus of Rigidity.

Aïdara M. L. C., Ba, M., \& Carter, A. (2015). Choice of an Advanced Model for Asphalt Concrete Rheological from Senegal (West Africa). Open Journal of Civil Engineering.

Di, B. H., \& Corté, J. F (2005). Road Bituminous Materials 2. Thermomechanical properties and components of mixtures. Lavoisier Edition. Hermès Science.

Doucet, F., \& Auger, B. (2010).Determination of complex modulus asphalt concretes to MTQ.RTQ-10-01.

Dougan, C. E, Jack, E., Mahoney, S. J., \& Hansen, G., (2003). E* - DYNAMIC MODULUS Test Protocol - Problems and Solutions Report Number CT-SPR-0003084-F-03-3. Connecticut Department of Transportation in 6. Cooperation with the U.S. Department of Transportation, Federal Highway Administration http://docs.trb.org/00941260.pdf

Huang, Y. H. (2004). Pavement Analysis and Design. Kentucky: PEARSON. Prentice Hall.

NCHRP. TRB. NRC. (2004). Guide for Mechanistic-Empirical Design-For new and rehabilitated pavement structures. Illinois: ARA. Inc. ERES Consultants Division.

Olard, F., \& DI Benedetto, H. (2003). General "2S2P1D" model and relation between the linear viscoelastic behaviors of bituminous binders and mixes. International Journal of Road Materials and Pavement Design,4(2), 185-224. (s.d.).

Papagiannakis \& Masad, E. (2007). Pavement Design and Materials. John Wiley and Sons. Inc. Hoboken. NJ.T. 552 pp.

Québec Transportation (2009). LC 26-700, Determination of Complex Modulus for Hot Mixtures Asphalt. MTQ Pavements Laboratory.

Raymond, G., \& Such, C. (2003). Complex modulus of asphalt binder. Research and study to Pavement and Bridge Laboratory. Reference: CR32.

Touhara, R. (2012). Asphalt concretes fatigue resistance study. Superior School of Technology.

Witczak, M. W., \& Kaloush. K. (2002). Simple Performance Test for Superpave Mix Design. Washington D.C.: Transportation Research Board. National Research Council.

Yoder, E. J., \& Witczak M. W. (1975). Principles of pavement design. John Wiley and Sons. 711. http://dx.doi.org/10.1002/9780470172919

\section{(cc) EY}

This work is licensed under a Creative Commons Attribution 3.0 License. 